\title{
Cystic fibrosis and allergic bronchopulmonary aspergillosis
}

\author{
E J Simmonds, J M Littlewood, E G V Evans
}

\begin{abstract}
We have prospectively screened our patients with cystic fibrosis for allergic bronchopulmonary aspergillosis. Over a three year period eight patients were identified, an incidence of $5.8 \%$. Patients were clinically well at the time of diagnosis (Shwachman scores 70-90, Chrispin-Norman chest $x$ ray scores 2-15) and they responded rapidly to treatment with oral prednisolone. There has been little deterioration in their respiratory function and nutrition over the study period.

We conclude that allergic bronchopulmonary aspergillosis is not uncommon in patients with cystic fibrosis. It is a potential cause of lung damage and prospective screening could lead to earlier detection and treatment.
\end{abstract}

There have been several reports of the association between allergic bronchopulmonary aspergillosis and cystic fibrosis. ${ }^{1-3}$ The diagnosis of allergic bronchopulmonary aspergillosis is based on a combination of clinical and laboratory findings; asthma, immediate cutaneous reactivity to Aspergillus fumigatus antigenic extracts, precipitating antibodies to $A$ fumigatus, raised total serum IgE concentrations, peripheral blood eosinophilia, pulmonary infiltrates on chest radiography, raised serum IgE and IgG antibodies to $A$ fumigatus, and proximal bronchiectasis. ${ }^{4}$ Other features include growth of the fungus from sputum, brown plugs in sputum, and a late (Arthus type) skin reaction to $A$ fumigatus. The diagnosis may be difficult to make in patients with cystic fibrosis as some of these features are common to both conditions.

Several workers have screened patients attending their cystic fibrosis clinics for the diagnostic features of allergic bronchopulmonary aspergillosis, and the reported incidence has varied from $0.6 \%$ to $11 \% .^{5-7}$ As a result of these reports we now screen all patients with cystic fibrosis who require intravenous treatment with antibiotics. We present our findings over the last three years.

Regional Cystic Fibrosis Unit, St James's University Hospital,

Leeds LS9 7TF

E I Simmonds

J M Littlewood

Regional Mycology

Laboratory,

University of Leeds

and General Infirmary,

Leeds

E G V Evans

Correspondence to:

Dr Simmonds.

Accepted 11 January 1990 Patients and methods

The case notes and radiographs of the 137 patients who were attending the Leeds regional cystic fibrosis unit for regular follow up at the end of 1988 were analysed for the three year period January 1986 to December 1988. During this time patients had been seen at least every two months for outpatient follow up, or between clinic visits if they were unwell. Chest radiographs were taken if they had increased respiratory symptoms, but if the patients remained well, they were done every six months.

Courses of intravenous treatment with antibiotics were started if there was clinical deterioration or if there were significant new radiographic changes. The antibiotics given were determined by the sensitivities in vitro of the pathogens most recently isolated from the sputum. Before treatment, blood was taken to estimate immunological measures of reaction to A fumigatus and sputum was cultured for fungal growth.

Patients were reviewed periodically during the course of treatment to confirm that progress was satisfactory. Those who had evidence of a new pulmonary infiltrate at the beginning of treatment had repeat radiographs taken after a week. If the infiltrate persisted, and laboratory results supported the diagnosis, allergic bronchopulmonary aspergillosis was considered likely. Skin testing to $A$ fumigatus antigen, if it had not been done recently, was carried out. A trial of high dose steroids was given ( $1-2 \mathrm{mg} / \mathrm{kg} /$ day prednisolone). The diagnosis was confirmed when clearing of the pulmonary infiltrates was associated with an improvement in the patient's condition. Steroids were then given on alternate days and the course was tapered off during the next six months.

The mean age of the 137 patients was $12 \cdot 8$ years (range $0 \cdot 8-32 \cdot 0)$. Seventy one $(52 \%)$ had evidence of obstructive airways disease, either because of a history of wheezing or because their respiratory function improved (a rise in forced expiratory volume in one second of $10 \%$ ) on testing with a bronchodilator. These 71 patients were treated with inhaled bronchodilators. Twenty five of these $(35 \%)$ were also having inhaled steroids, and two patients inhaled sodium cromoglycate.

\section{SKIN TESTING}

Aspergillus antigen (Bencard) prick testing was carried out on the forearm. A control solution was used on the opposite arm and the reactions compared 15 minutes later. A reaction was considered positive if the weal was at least $3 \mathrm{~mm}$ diameter more than that of the control, and the
SERUM IgE

Total serum IgE was measured with a competitive radioimmunoassay kit (Pharmacia Ltd). Specific IgE to A fumigatus was measured by radioallergosorbent test (RAST) (Pharmacia 
Ltd). Positive responses were compared with standards and graded $0-4$.

PRECIPITINS TO A FUMIGATUS

Precipitins were detected by counterimmune electrophoresis of serum dilutions against somatic and culture filtrate antigens of $A$ fumigatus (Mercia Diagnostics Ltd) as described previously. ${ }^{8}$

\section{EOSINOPHILIA}

Differential white cell counts were measured by image analysis using standard laboratory equipment (Hematrak 590). A value $>0.4 \times 10^{9} / 1$ was regarded as supporting the diagnosis of allergic bronchopulmonary aspergillosis.

\section{SPUTUM CULTURE FOR A FUMIGATUS}

Sputum was mixed with an equal volume of dithiothreitol (Sputasol, Oxoid) and incubated at $37^{\circ} \mathrm{C}$ to digest it. A $10 \mu$ l aliquot was plated out on Sabouraud's medium containing colomycin at a strength of $13 \mathrm{mg} / \mathrm{l}$. The plates were incubated at $37^{\circ} \mathrm{C}$ and inspected daily for fungal growth.

\section{PULMONARY INFILTRATE}

This was defined as a confluent opacity on chest radiograph measuring more than $1 \mathrm{~cm}$ in two separate diameters. Areas of segmental or lobar collapse were also included in this definition.

\section{CLINICAL SCORES}

The Shwachman score grades the clinical state of patients with cystic fibrosis. ${ }^{9}$ Points are allocated for general activity, physical examination, nutrition, and radiographic findings. A total of 100 points are possible; a higher score indicates a better clinical condition.
The Chrispin-Norman score grades the severity of changes seen on chest radiographs in patients with cystic fibrosis. ${ }^{10} \mathrm{~A}$ total of 38 points may be allocated; higher scores are given for more severe disease.

\section{Results}

Ninety nine $(72 \%)$ of the 137 patients required intravenous treatment with antibiotics during the three years of the study period. A total of 339 courses were given to these patients of which $54(16 \%)$ were associated with new pulmonary infiltrates. Eleven (20\%) of these episodes were subsequently diagnosed as allergic bronchopulmonary aspergillosis and they occurred in eight $(6 \%)$ of the patients.

At the time of diagnosis six of the eight patients had increased respiratory symptoms. The remaining two were stable with minimal symptoms and were detected from their routine six monthly radiographs. As a group these patients represented $11 \%$ of the patients with airways obstruction, although they had little other evidence of atopy. One patient had nasal polyps with perennial rhinitis, and another had allergic rhinitis. No patient had a history of eczema or food allergy.

The ages of the patients with allergic bronchopulmonary aspergillosis ranged from 6-20 years at the time that it was first diagnosed. They were all in good condition (Shwachman scores 70-90) with mild or moderate radiological evidence of cystic fibrosis (Chrispin-Norman scores 2-15). Only three patients were chronically infected with Pseudomonas aeruginosa (table 1).

As well as new pulmonary infiltrates all patients had immediate skin sensitivity to A fumigatus, an appreciable degree of reversible airways disease, $A$ fumigatus precipitins (one patient was not tested), and positive $A$ fumigatus specific IgE. Six of the patients had eosinophilia, seven had raised total serum IgE concentrations, and seven grew $A$ fumigatus in their

Table 1 Clinical condition at time of diagnosis of allergic bronchopulmonary aspergillosis

\begin{tabular}{llllcl}
\hline Case No & $\begin{array}{l}\text { Date of } \\
\text { diagnosis }\end{array}$ & $\begin{array}{l}\text { Age } \\
\text { (years) }\end{array}$ & $\begin{array}{l}\text { Shwachman } \\
\text { score }\end{array}$ & $\begin{array}{l}\text { Chrispin-Norman } \\
\text { score }\end{array}$ & Normal bacterial pathogen \\
\hline 1 & May 1986 & 6 & 75 & 5 & Pseudomonas aeruginosa \\
2 & July 1986 & 12 & 90 & 5 & Staphylococcus aureus and Haemophilus influenzae \\
3 & June 1987 & 15 & 90 & 6 & No growth \\
4 & August 1987 & 20 & 75 & 12 & Pseudomonas aeruginosa \\
5 & September 1987 & $12 \cdot 5$ & 85 & 8 & Haemophilus influenzae and Staphylococcus aureus \\
6 & October 1987 & 10 & 70 & 12 & Staphylococcus aureus and Haemophilus influenzae \\
7 & November 1987 & 11 & 75 & 15 & Pseudomonas aeruginosa \\
8 & September 1988 & 8 & 95 & 2 & No growth \\
\hline
\end{tabular}

Table 2 Diagnostic features of allergic bronchopulmonary aspergillosis

\begin{tabular}{|c|c|c|c|c|c|c|}
\hline $\begin{array}{l}\text { Case } \\
\text { No }\end{array}$ & Appearance on chest radiograph & $\underset{(\mu g / l)}{\operatorname{IgE}}$ & $\begin{array}{l}\text { RAST to } \\
\text { A fumigatus } \\
\text { (grade) }\end{array}$ & $\begin{array}{l}\text { Precipitins } \\
\text { (serum dilutions) }\end{array}$ & $\begin{array}{l}\text { Eosinophils } \\
\left(\times 10^{9} / l\right)\end{array}$ & $\begin{array}{l}\text { A fumigatus } \\
\text { in sputum }\end{array}$ \\
\hline $\begin{array}{l}1 \\
2 \\
3 \\
4 \\
5 \\
6 \\
7\end{array}$ & $\begin{array}{l}\text { Left upper lobe collapse/consolidation } \\
\text { Right lower lobe consolidation } \\
\text { Left upper lobe consolidation } \\
\text { Left upper lobe linear atelectasis } \\
\text { Right upper lobe consolidation } \\
\text { Right middle lobe collapse/consolidation } \\
\text { Right mid lobe and left upper lobe }\end{array}$ & $\begin{array}{r}864 \\
3600 \\
5040 \\
7560 \\
1200 \\
504\end{array}$ & $\begin{array}{l}2 \\
3 \\
2 \\
1 \\
2 \\
2\end{array}$ & $\begin{array}{l}\text { Not available } \\
1 / 16 \\
1 / 1 \\
1 / 8 \\
1 / 4 \\
1 / 32\end{array}$ & $\begin{array}{l}1 \cdot 260 \\
0 \cdot 428 \\
0 \cdot 686 \\
1 \cdot 050 \\
0 \cdot 252 \\
2 \cdot 074\end{array}$ & $\begin{array}{l}\text { Positive } \\
\text { Negative } \\
\text { Positive } \\
\text { Positive } \\
\text { Positive } \\
\text { Positive }\end{array}$ \\
\hline 8 & & $\begin{array}{r}5400 \\
115\end{array}$ & $\begin{array}{l}2 \\
1\end{array}$ & $\begin{array}{l}1 / 8 \\
1 / 8\end{array}$ & $\begin{array}{l}0.112 \\
0.661\end{array}$ & $\begin{array}{l}\text { Positive } \\
\text { Positive }\end{array}$ \\
\hline
\end{tabular}


sputum (table 2). All patients responded to courses of oral steroids.

The patients with allergic bronchopulmonary aspergillosis have been followed up for one to three years, and there has been little overall change in their respiratory function and nutrition during this period. Case 2 had a pronounced improvement in his respiratory function, which could be accounted for by more vigorous treatment of $P$ aeruginosa infection after transfer to our unit. Two patients have had relapses since their original diagnosis and treatment.

The following two case reports illustrate some of the problems of management.

\section{CASE 8}

This patient was referred at the beginning of 1987 aged 6.8 years in good clinical condition. Eighteen months after her referral she developed symptoms of asthma with a troublesome cough at night and occasional wheezing. A chest radiograph at this time showed only mild hyperinflation.

She improved temporarily when treated with an inhaled $\beta_{2}$ agonist and inhaled steroids, but after renewed symptoms, loss of $1 \mathrm{~kg}$ in weight, and a sputum culture that grew $P$ aeruginosa she was admitted for an intravenous course of piperacillin and tobramycin.

There was no improvement after one week's treatment. A chest radiograph showed left upper lobe collapse and consolidation, and sputum was reported as growing $A$ fumigatus only. The results of blood tests did not confirm the diagnosis (table 1) but treatment with oral

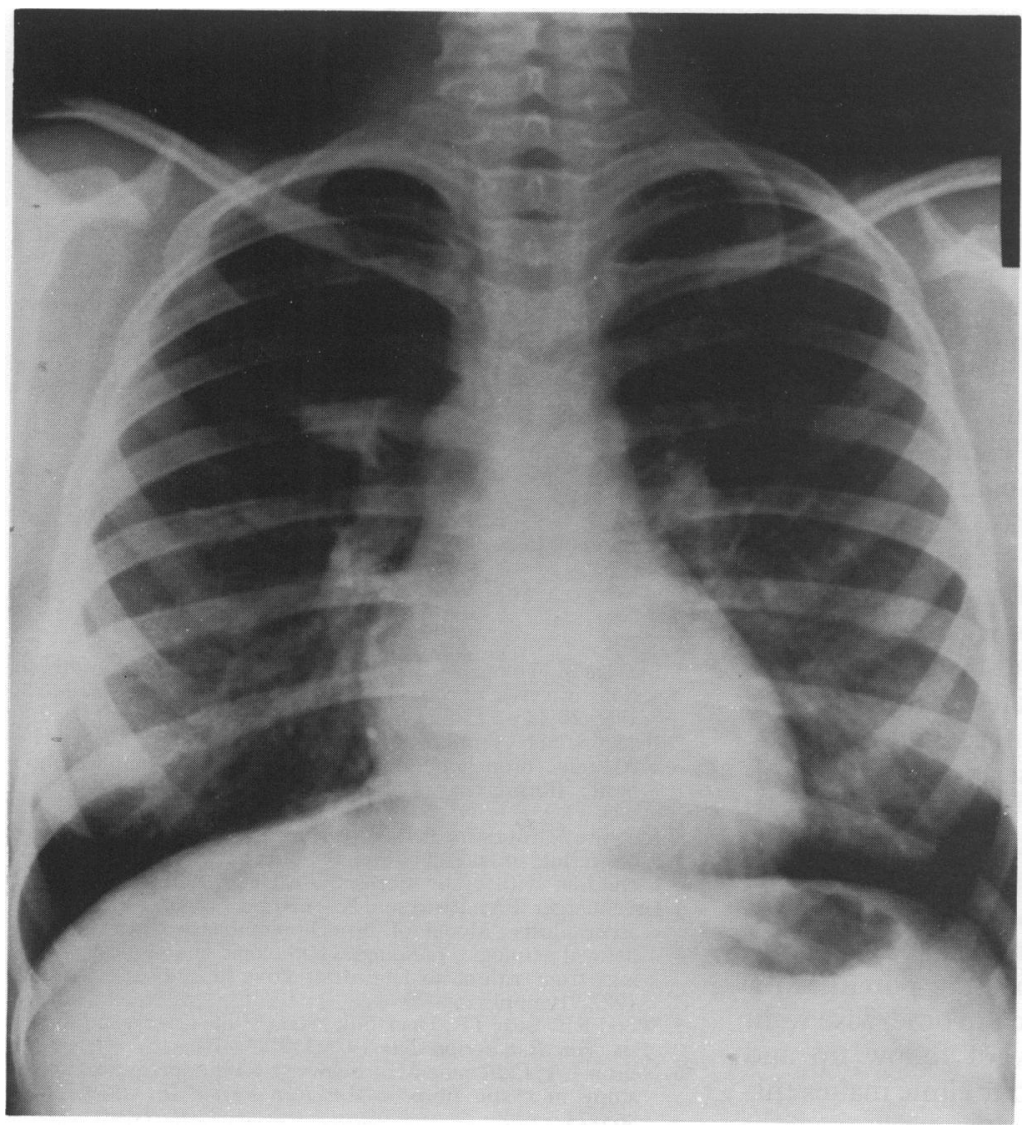

prednisolone $(1 \mathrm{mg} / \mathrm{kg} /$ day $)$ resulted in some improvement on the chest radiograph one week later, and full resolution of previously noted acute changes after one month's treatment with steroids. Her symptoms completely resolved and she regained weight. Four months after her original illness she was well on maintenance treatment with inhaled beclomethasone.

\section{CASE 5}

This patient was transferred to our unit at the age of 11 years. She was in good clinical condition with evidence of reversible airways disease on testing. Regular treatment with a bronchodilator was advised.

One year later she developed a persistent cough that did not respond to oral treatment with flucloxacillin and amoxycillin. A chest radiograph showed right upper lobe consolidation (figs 1 and 2). A diagnosis of allergic bronchopulmonary aspergillosis seemed likely as she fulfilled most of the established criteria (table 2) and a course of oral steroids was prescribed; the medication was not given, however, because of her parents' anxieties about the potential side effects. Her symptoms persisted despite inpatient intravenous treatment with piperacillin, lincomycin, and cloxacillin. Acute changes on the chest radiograph were unchanged, and results of immunological investigations continued to support the diagnosis of allergic bronchopulmonary aspergillosis. Her parents remained reluctant for her to be given steroids. Her symptoms settled over the next two months with spontaneous resolution of radiographic changes, but with evidence of residual right upper lobe contraction.

One year later the routine radiograph showed right upper lobe consolidation; the diagnosis of allergic bronchopulmonary aspergillosis again seemed likely. After a 14 day course of enteric coated prednisolone prescribed by her general practitioner there were no changes on the radiograph. The consolidation cleared, however, after treatment with a non-enteric coated preparation. Residual right upper lobe contraction remained as before. Five months later she remained well, taking $10 \mathrm{mg}$ prednisolone on alternate days.

\section{Discussion}

The importance of $A$ fumigatus in patients with cystic fibrosis remains controversial. Many patients have evidence of sensitisation to the fungus, ${ }^{11-13}$ and there is a smaller number who fulfil the diagnostic criteria for allergic bronchopulmonary aspergillosis. ${ }^{6} 7$ Progressive destruction of the lungs leading to end stage fibrotic lung disease and respiratory failure has been described in asthmatic patients with the disease. ${ }^{14}$ As sensitisation to $A$ fumigatus in patients with cystic fibrosis is associated with decreased lung function and poorer clinical condition, ${ }^{11-13}$ it has been postulated that it might contribute to lung damage. ${ }^{15}$ 


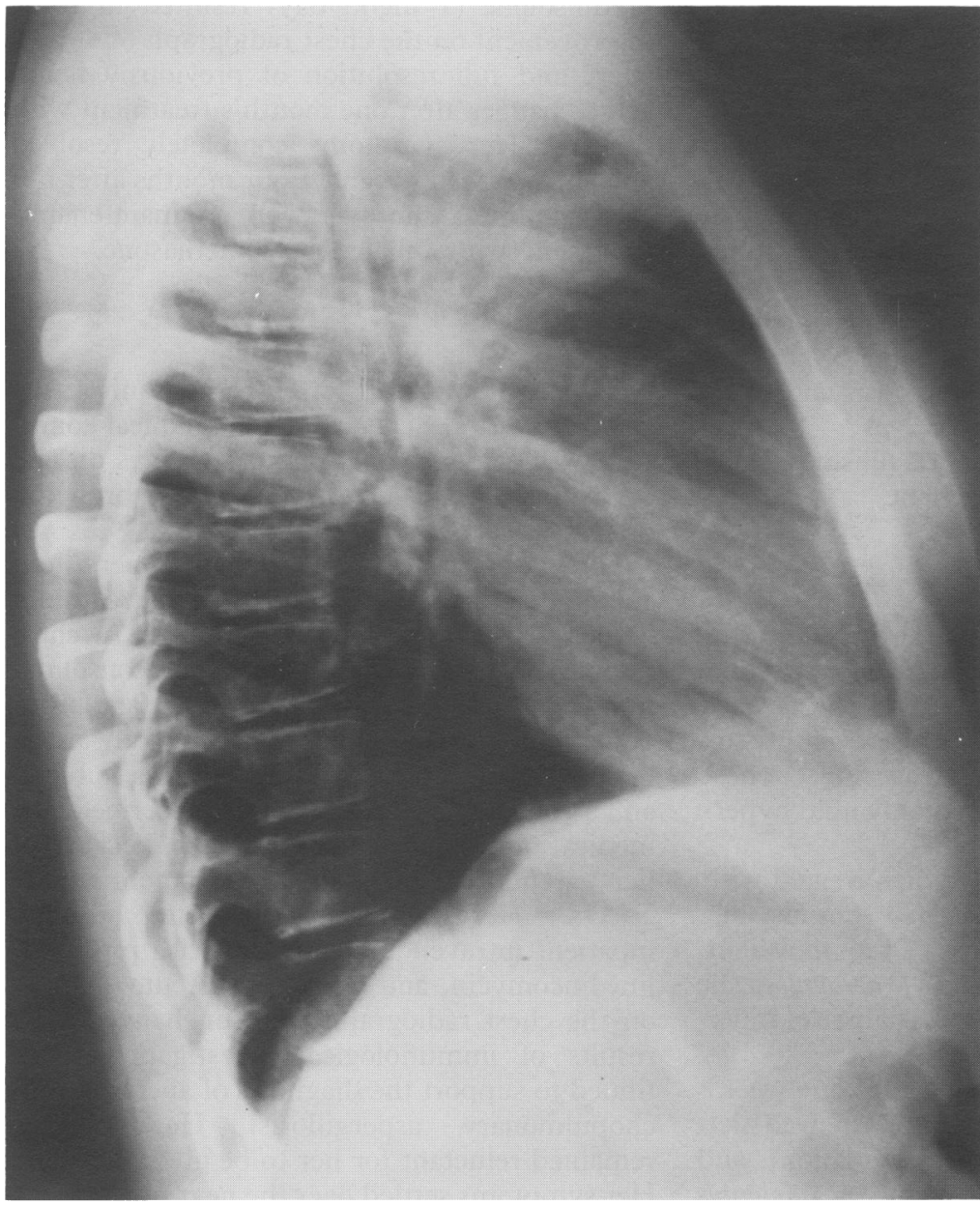

Figure 2 Case 5: consolidation/collapse of anterior segment of right upper lobe; lateral view.
Allergic bronchopulmonary aspergillosis has been described in patients with normal radiographs ${ }^{18}$ and this is another reason for it to be missed. The diagnosis was confirmed by the finding of proximal bronchiectasis on bronchography, a procedure likely to be hazardous in patients with cystic fibrosis. Moreover, proximal bronchiectasis is common to both conditions.

Prednisolone given orally is now well established as the treatment of choice for allergic bronchopulmonary aspergillosis. The dose of steroids that we used is higher than that normally recommended, ${ }^{19}$ but this is based on anecdotal experience of poor response to conventional regimens.

It is important to ensure that non-enteric coated preparations are given, as enteric coated steroids may not be satisfactorily absorbed in patients with cystic fibrosis (case 5 ). ${ }^{20}$ Treatment with high doses of steroids can provoke diabetes mellitus in these patients (case 7) and this complication must be regularly sought. Long term treatment may result in stunting of growth and osteoporosis. We hope that new oral antifungal agents will provide an alternative, both for treatment of acute episodes of allergic bronchopulmonary aspergillosis and for prophylaxis against future attacks. ${ }^{21}$

Modern management of cystic fibrosis has led to an increase in life expectancy of patients within the United Kingdom. ${ }^{22}$ This has been achieved as a result of more intensive treatment for improving nutrition and controlling respiratory infection. Many young patients have minimal symptoms, mild radiographic changes, and well preserved respiratory function. It is within this group of patients that allergic bronchopulmonary aspergillosis has presented a problem.

We conclude that allergic bronchopulmonary aspergillosis is not uncommon in patients with cystic fibrosis and should be considered in all patients in whom new pulmonary infiltrates are seen on chest radiography. We suggest that prospective screening of patients with regular assessment of both radiographs and immunological reactions to $A$ fumigatus may detect cases early. This is important, because prompt treatment may prevent lung damage that is not caused by bacteria.

Over the three year study period of our patients with cystic fibrosis eight $(5 \cdot 8 \%)$ developed allergic bronchopulmonary aspergillosis; further episodes occurred in two patients during the same time (a total of 11 episodes). In our cases the diagnosis was confirmed by radiological and clinical improvement after treatment with steroids, when there had been no improvement with standard antibacterial treatment-a criteria rarely mentioned in previous reports. This is important, because pulmonary infiltrates in cystic fibrosis may have other causes, particularly bacterial infections.

This may be an underestimate of the true incidence of the disease. Allergic bronchopulmonary aspergillosis often resolves spontaneously (case 5) and thus has the potential for being missed in patients who are otherwise well. We feel that the regularity of follow up and radiological examination in our clinic makes this unlikely.
We thank the Cystic Fibrosis Research Trust for funding Dr E J Simmonds.

1 Mearns M, Young W, Batten J. Transient pulmonary infiltrations in cystic fibrosis due to allergic aspergillosis. Thorax 1965;20:385-92.

2 Brueton MJ, Ormerod LP, Shah KH, Anderson CM Allergic bronchopulmonary aspergillosis complicating cystic fibrosis in childhood. Arch Dis Child 1980;55: 348-53.

3 Maguire S, Moriarty P, Tempany E, Fitzgerald M. Unusual clustering of allergic bronchopulmonary aspergillosis in children with cystic fibrosis. Pediatrics 1988;82:835-9.

4 Greenberger PA, Patterson R. Allergic bronchopulmonary aspergillosis. Model of bronchopulmonary disease with defined serologic, radiologic, pathologic and clinical findings from asthma to fatal destructive lung disease. Chest 1987;91(suppl): 165-70.

5 Wood RE, Boat TF, Doershuk. State of the art-cystic fibrosis. Am Rev Respir Dis 1976;113:833-78.

6 Nelson LA, Callerame ML, Schwartz RH. Aspergillosis and atopy in cystic fibrosis. Am Rev Respir Dis 1979;120: 863-73. 
7 Zeaske R, Bruns WT, Fink JN, et al. Immune response to aspergillus in cystic fibrosis. F Allergy Clin Immunol 1988;

8 Evans EGV. Serology of fungal infection and farmer's lung disease. A laboratory manual. Leeds: British Society for Mycopathology, 1976

9 Shwachman H, Kulczycki LL. Long term study of one hundred and five patients with cystic fibrosis. $A M A$ Fournal of Diseases of Children 1958;96:6-15.

10 Chrispin AR, Norman AP. The systematic evaluation of the chest radiograph in cystic fibrosis. Pediatr Radiol 1974;2: 101-5.

11 Mearns M, Longbottom J, Batten J. Precipitating antibodie to Aspergillus fumigatus in cystic fibrosis. Lancet 1967; 538-9.

12 Warner JO, Taylor BW, Norman AP, Soothill JF. Association of cystic fibrosis with allergy. Arch Dis Child 1976;51: 507-11

13 Forsyth KD, Hohmann AW, Martin AJ, Bradley J. IgG antibodies to Aspergillus fumigatus in cystic fibrosis: a laboratory correlate of disease activity. Arch Dis Child 1988;63: tory corre.

14 Lee TM, Greenberger PA, Patterson R, Roberts M, Liotta JL. Stage V (fibrotic) allergic bronchopulmonary aspergillosis. Arch Intern Med 1987;147:319-23.
15 Schonheyder H, Jenson T, Laessof IH, Hoiby N, Koch C. Serum antibodies to Aspergillus fumigatus catalase in patients with cystic fibrosis. European fournal of

16 Henry RL, Mellis CM, Simpson SJ, South RT. Allergic bronchopulmonary aspergillosis in cystic fibrosis. Aust Paediatr f 1982;18:110-3.

17 Pitcher-Wilmott RW, Levinsky RJ, Gordon I, Turner MW, Matthew DJ. Pseudomonas infection, allergy and cystic fibrosis. Arch Dis Child 1982;57:582-6.

18 Rosenberg M, Mintzer R, Aarouson DW, Patterson R. Allergic bronchopulmonary aspergillosis in three patients with normal chest x-ray. Chest 1977;72:597-600.

19 Wang JLF, Patterson R, Roberts M, Ghory A. The management of allergic bronchopulmonary aspergillosis. Am Rev Respir Dis 1979;120:87-92.

20 Gilbert J, Littlewood JM. Enteric coated prednisolone in cystic fibrosis. Lancet 1986;ii:1167-8.

21 Van Cutsen J, Van Gerven F, Van de Ven M, Borgers $M$ Janssen PAJ. Itraconazole; a new triazole that is orally active in aspergillosis. Antimicrob Agents Chemother 1984;

22 British Paediatric Association Working Party on Cystic
Fibrosis. Cystic Fibrosis in the United Kingdom 1977Fibrosis. Cystic Fibrosis in the United Kingdom 1977- 